\title{
A Blended Collaborative Teaching and Learning Model for Chinese L2 learners Based on Website
}

\author{
Jiangying $\mathrm{Yu}^{*}$ \\ School of International Exchange, Yunnan Open University, Kunming Yunnan 650223, China; \\ Institute of Big Data and Language Education, Beijing Language and Culture University,Beijing \\ 10083,China \\ *yujiangying2008@qq.com
} Keywords: Blended Learning; Chinese as a second language (L2); Open and Distance Learning
(ODL); model.

\begin{abstract}
Blended Learning is not a new term in Open and Distance Learning (ODL), which has been used with increased frequency in both academic and corporate circles since the beginning of the last century. However, the study on Chinese as a second language (L2) teaching and learning with the application of Blended Learning Theory is still relatively rare. This paper outlines a blended collaborative teaching and learning Model for whom learning Chinese as second language (L2) based on the network platform (ynou.myechiese.com) independently designed by Yunnan Open University. This paper will share some trends and issues that are highly relevant to Chinese as a second language (L2) teaching and learning based on network platform. To accomplish the goal, this paper will address three important questions related to Blended Learning: First, What is the exact definition of Blended Learning in this study? Why a Chinese learner who learns Chinese as a second language (L2) might pick Blended Learning over other learning options? How the current blended collaborative teaching and learning model exist? Discussion on the above problems is based on practice, so this study is an applied research, which might play an important revelation and significance for the application of Open and Distance Learning (ODL) in Chinese as a second language (L2) teaching and learning.
\end{abstract}

\section{Introduction}

We live in a world in which technological innovation is occurring at break-neck speed and digital technologies are increasingly becoming an integral part of our day-to-day lives.Technological innovation is also expanding the range of possible solutions that can be brought to bear on teaching and learning.

As we know, we have the traditional face-to-face (F2F) learning environment that has been around for centuries. On the other hand, we have distributed learning environments that have begun to grow and expand in exponential ways as new technologies have expanded the possibilities for distributed communication and interaction. The rapid emergence of technological innovations over the last half century (particularly digital technologies) has had a huge impact on the ongoing convergence of these two archetypal learning environments.

Definition of Blended Learning. The term "blended learning" is being used with increased frequency in academic circles.In 2002, The Chronicle of Higher Education quoted the president of Pennsylvania State University as saying that the convergence between online and residential instruction was "the single-greatest unrecognized trend in higher education today" (Young, 2002, p.A33). Also quoted in that article was the editor ofThe Journal of Asynchronous Learning Networks who predicted a dramatic increase in the number of hybrid (i.e., blended) courses in higher education, possibly to include as many as $80-90 \%$ of all courses (Young, 2002).

So what is this "blended learning" that everyone is talking about? This paperwill provide a basic introduction to blended learning and share some trends and issues that are highly relevant to Chinese 
as a second language (L2) teaching and learning based on network platform. To accomplish these goals, the paper will first address one important question related to blended learning: What is blended learning?

What is being blended? One frequent question asked when one hears about blended learning (BL) is “What is being blended?”While there are a wide variety of responses to this question (Driscoll, 2002), most of the definitions are just variations of a few common themes. The three most commonly mentioned definitions documented by Graham, Allen, and Ure (2003) are:

1) $\mathrm{BL}=$ combining instructional modalities (or delivery media) (Bersin \& Associates, 2003; Orey, 2002a, 2002b; Singh \& Reed, 2001;)

2) $\mathrm{BL}=$ combining instructional methods (Driscoll, 2002; Rossett, 2002)

3) $\mathrm{BL}=$ combining online and face-to-face instruction (Reay, 2001; Rooney, 2003; Ward \& LaBranche, 2003; Young, 2002)

The first two positions above reflect the debate on the influences of media versus method on learning. Both of these positions suffer from the problem that they define BL so broadly that there encompass virtually all learning systems. One would be hard pressed to find any learning system that did not involve multiple instructional methods and multiple delivery media. So defining BL in either of these two ways waters down the definition and really does not get at the essence of what blended learning is and why the concept of blended learning is exciting to so many people. The third position more accurately reflects the historical emergence of blended learning. Itis also the foundation of the author's working definitionthat Blended learning (BL) combines face-to-face instruction with computer-mediated instruction.

According to the author's working definition, BL is the combination of instruction from two historically separate models of teaching and learning: traditional F2F learning environment and distributed learning environments.It also emphasizes the central role of computer-based technologies in blended learning.BL is part of the ongoing convergence of two archetypal learning environments. In the past, these two archetypal learning environments have remained largely separate because they have used different media/method combinations and have addressed the needs of different audiences (see Figurequoted from Graham, 2004). For example, traditional F2F learning typically occurred in a teacher-directed environment with person-to-person interaction in a live synchronous, high fidelity environment. On the other hand, distance learning systems emphasized self-paced learning and learning-materials interactions that typically occurred in an asynchronous, low fidelity (text only) environment. 


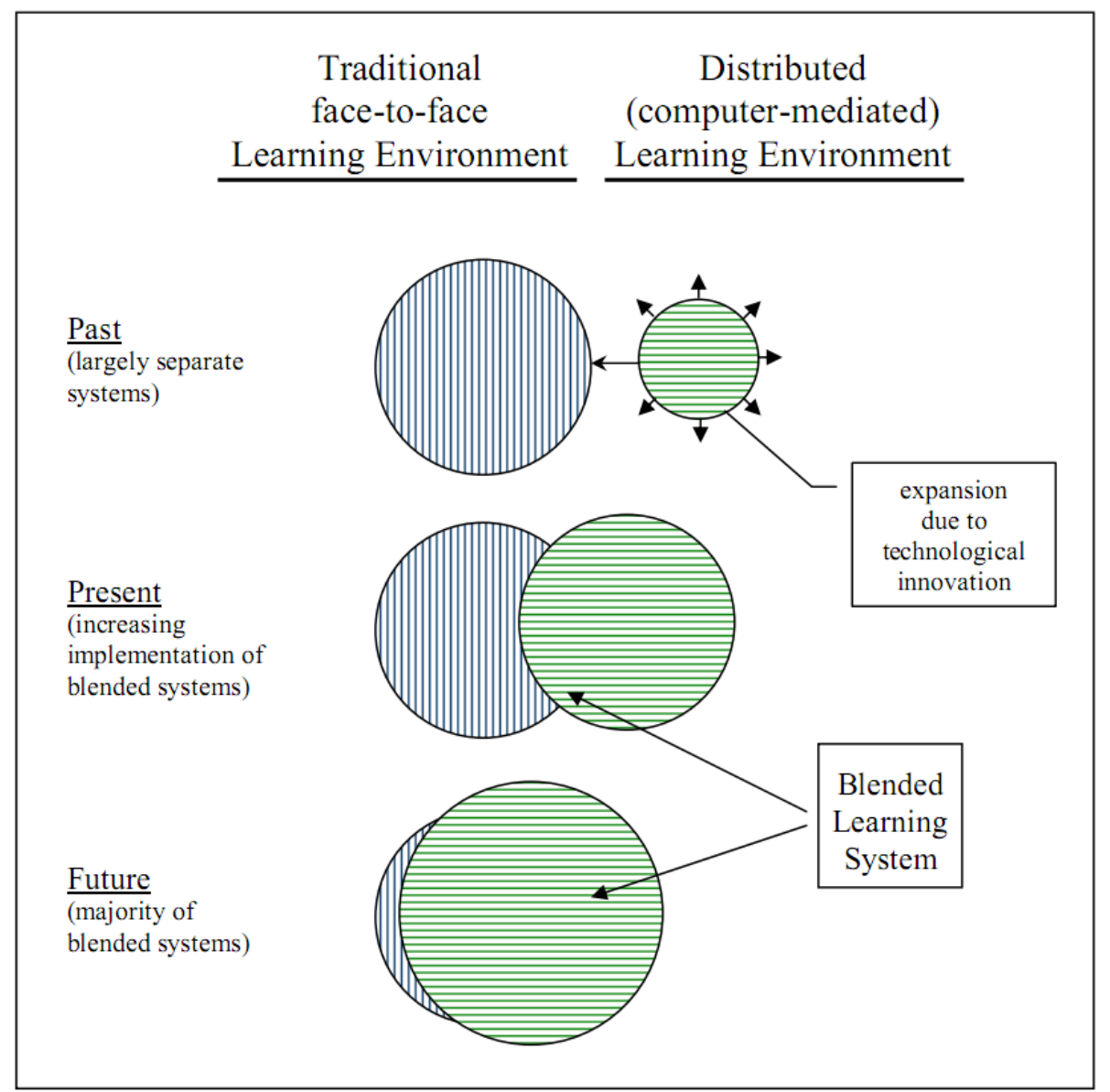

Figure: Progressive convergence of traditional F2F and distributed environments allowing development of blended learning systems (quoted from Graham, 2004)

Why we pick BL over other learning options? There are many reasons why an instructor, trainer, or learner might pick BL over other learning options. Osguthorpe and Graham (2003) identified six reasons why one might choose to design or use blended learning:(1) pedagogical richness, (2) access to knowledge, (3) social interaction, (4) personal agency, (5) cost effectiveness, and (6) ease of revision.In the BL literature, the most common reason provided is that BL combines "the best of both worlds" (refs). While there is some truth to this, it is rarely acknowledged that a blended learning environment can also mix the least effective elements of both worlds if it is not designed well. Beyond this general statement, Graham et al. (Graham, Allen, \& Ure, 2003, in press) found that overwhelmingly people chose BL for three reasons: (1) improved pedagogy, (2) increased access/flexibility, and (3) increased cost effectiveness.

Improved Pedagogy. As indicated above, one of the most commonly cited reasons for blending is more effective pedagogical practices. It is no secret that most current teaching and learning practice is still focused on transmissiverather than interactive strategies. In higher education, $83 \%$ of instructors use the lecture as the predominant teaching strategy (U.S. Department of Education, 2001).Similarly, distance education often suffers from making large amounts of information available for students to absorb independently (Waddoups \& Howell, 2002).

Some have seen blended learning approaches increase the level of active learning strategies, peer-to-peer learning strategies, and learner centered strategies used. For example, with the Chinese language learning networkplatform (ynou.myechiese.com), Chinese L2 learners can go through two phases (Phase 1) online self-paced Chinese learning focused on inputting and acquiringChinese languagepoints, (Phase 2) offline or F2F interactive Chineselanguage classroom activities focused on outputtinginstead of inputting. A few other ideas for using BL to improve pedagogy included in the Chinese learning network platformare: It provides insights into how computer-mediated environments can bring a level of authenticity to the traditional classroom experience with the application of ASR (Automatic Speech Recognition);Itshares a model for how BL can be used to 
integrate formal classroom learning and informal workplace learning with the adoption of featured internship programs; Itshares ideas for collaborative learning and problem solving with the help of the Open Meeting System.

IncreasedAccess/Flexibility. Access to learning is one of the key factors influencing the growth of blended learning. It is well-known that BLwould not be possible if students were not able to have a majority of their learning experiences at a distance from instructors or other students. Learner flexibility and convenience is also of growing importance as more mature learners with outside commitments (such as workand family) seek additional education. Many learners want the convenience offered by a distributed environment, and, at the same time, do not want to sacrifice the social interaction and human touch they are used to in a F2F classroom.

There are numerous examples in the blended collaborative teaching and learning modelfor Chinese L2 learners of how blending is used to provide a balance between flexible learning options and the high touch human interactive experience. Immersion Chinese language Camp, for example, has seen an expansion of reduced seat time courses that allow for increased flexibility but retain some traditional F2F contact. As a second example, Featured Internship programs allow for F2F socializing in orientations as well as presentation experiences at the beginning and ending of a course with online learning experiences in between.

Increased Cost Effectiveness. Cost effectiveness is a third major goal for BL. Blended learning provides an opportunity for reaching a large, globally dispersed audience in a short period of time with consistent, semi-personal content delivery. Yunnan Open University Chinese Language Learning Center in Bangladesh(established in Jun,2013)have done an exemplary job of expanding enrollmentthat have effectively used blended learning to provide a large returnon investment (ROI). In adding to these results, Yunnan Open University Chinese Language Learning Center in Nepal and Indiaboth provide cases in which BL solutions have resulted in a significant ROI.

How the blended collaborative teaching and learning model for Chinese L2 learners exist? One of the reasons that we are interested in models of blended learning is that we are interested in the practical question of "How to blend?" Each model provides ideas about how to blend with examples implemented in specific contexts and with real constraints. It is acknowledged that different models of blending occur at a variety of different organizational levels. This section will articulate the threedifferent levels at which we identified blends occurring: 1) Course level;2)Programlevel;3) Activity level.It is important to note that none of these blends are necessarily bad -they just have different foci. The blended collaborative teaching and learning model providethree levels for Chinese L2 learnersbased on the network platform.Across all three levels, the nature of the blends is either determined by the learner or the designer/instructor. Blending at the course and program levels is often left to the discretion of designers/instructors, while the learner is more likely to take a role in prescribing the blend at the activity level.

Course Level Blending. Course level blending is one of the most common ways to blend. A course level blend entails a combination of distinct ONLINE and OFFLINE (F2F)courses.Correspondingly, the diverselearning resources and multiple delivery media must be combined and blended.On the one hand,Chinese L2 learners can beengaged in ONLINE and OFFLINE (F2F)coursesthat overlap in time or sequence chronologically. On the other hand,the diverse learning resources and multiple delivery media will be provided for Chinese L2 learners.

Program Level Blending. Blends in education are often occurring at the degree program and non-degree program levels. Andthe blended collaborative teaching and learning modelfor Chinese L2 learnersis also no exception. Blending at a program level often entails a combination oftwotypes of programs Formal and Non-formal. For example, if you want to apply for bachelor degree of Hospitality Management, you should participate in the non-degree language programfirst, which allows you the choice of completing the program completely online or online with F2F tutoring session.

Activity Level Blending. Blending at the activity level occurs when a learning activity contains variable learningstrategies such as interactive learningstrategies,learner centered strategies and peer-to-peer learning strategies.For example,peer-to-peer learning strategiesshould be used when the 
ChineseL2 learnergoes through online self-paced Chinese learning, while interactive learning strategiesshould be used when he goes offline or F2FChineselanguage classroom activities.

Future Work. The blended collaborative teaching and learning Model for ChineseL2 learner based on the network platform (ynou.myechiese.com)most likely to encounter the main issue: Cultural Adaptation. What role can and should blended approaches play in adapting materials to local audiences. One strength of e-learning is the ability to rapidly distribute uniform learning materials. Yet, there is often a need for customizing the materials to the local audience to make them culturally relevant. We address the need to find balance between global and local interests and suggest that a F2F instructor plays an important role in helping to make globally distributed materials culturally relevant and meaningful.

As we move into the future it is important that we continue to identify successful models of blended learning at the course, program, and activity levels that can be adapted to work in contexts. This will involve understanding and capitalizing on the unique affordances available in both F2F and computer-mediated or distributed learning environments.

\section{References}

[1]Bersin \& Associates. Blended learning: What works? 2003,Oakland, CA: Bersin by Deloitte. Ret rieved December 5, 2016, from https://education-2020.wikispaces.com/file/view/blended_bersin.doc

[2]JK Williams. The Handbook of Blended Learning: Global Perspectives, Local Designs by Curtis J. Bonk; Charles R. Graham [J]. Academy of Management Learning \& Education,2008, 7 (1):132-133.

[3] M Driscoll.Blended Learning: Let's get beyond the hype,2002, Retrieved December 5, 2016, from https://www.researchgate.net/publication/286029739_Blended_learning_Let\%27s_get_beyon d the hype

[4] Sophonhiranrak S., Suwannatthachote P., Ngudgratoke S. Factors Affecting Creative Problem Solving in the Blended Learning Environment: A Review of the Literature[J]. Procedia-Social and Behavioral Sciences, 2015, 174(21)30-36.

[5] Bridges S., Chang JW., Chu CH. Gardner K. Blended learning in situated contexts: 3-year evaluation of an online peer review project[J]. European Journal of Dental Education Official Journal of the Association for Dental Education in Europe, 2014, 18(3):170-179.

[6] Krasnova T. A Paradigm Shift: Blended Learning Integration in Russian Higher Education, Procedia - Social and Behavioral Sciences ,2015, (166):399-403.

[7] Erpenbeck J., Sauter S., Sauter W. E-Learning and Blended Learning[M].New York:Springer Fachmedien Wiesbaden,2015:43-46.

[8] Garrison D R, Kanuka H. Blended learning: Uncovering its transformative potential in higher education[J]. Internet \& Higher Education, 2004, 7(2):95-105.

[9] Osguthorpe R T, Graham C R. Blended Learning Environments: Definitions and Directions[J]. Quarterly Review of Distance Education, 2003, 4(3):27-33.

[10] Singh H. Building Effective Blended Learning Programs[J]. Educational Technology, 2003, 43(6): 51-54. 